\title{
Does Familial History of Cancer Affect the General Health Conditions and Healthy Lifestyle Behavior of Nursing and Midwifery Students?
}

\author{
Feride Taşkın Yılmaz ${ }^{1}$, Azime Karakoç Kumsar ${ }^{2}$, Gülbahtiyar Demirel ${ }^{3}$, \\ Kadriye Aldemir ${ }^{4}$ \\ ${ }^{\text {I}}$ (Department of Internal Diseases Nursing, School of Susehri Health High, Cumhuriyet University, Turkey, RN, \\ PhD, Assist. Prof) \\ ${ }_{2}^{2}$ (Department of Internal Diseases Nursing, Faculty of Healthy Science, Biruni University, Turkey, RN, PhD, \\ Assist. Prof) \\ ${ }^{3}$ (Midwifery Department, Faculty of Health Science, Cumhuriyet University, Turkey, RN, PhD, Assist. Prof) \\ ${ }^{4}$ (Cumhuriyet University, School of Susehri Health High, Department of Surgical Diseases Nursing, Turkey, RN, \\ $M S c$, Lecturer)
}

\begin{abstract}
Aim: This study was performed with the aim of determining the effect of status regarding having a cancer patient in the family to the general health condition and healthy lifestyle behavior of nursing and midwifery students.

Method: A total of 713 students participated in the comparative and descriptive study. Data was collected using the student identification form, the General Health Questionnaire-12, and the Healthy Lifestyle Behavior ScaleII.

Results: Among the students, $23.7 \%$ had a cancer patient in their family, and those students were found to think they carried a higher risk for cancer $(p<0.01)$. It was determined that the general health statuses of the students with cancer patients in their families were affected on a higher level, although this difference was not statistically meaningful ( $p>0.05$ ). Additionally, the health responsibility and interpersonal relationships score averages, as well as the total scores of the students who had a cancer patient in their family were found to be higher compared to the students who didn't $(p<0.05)$. In the study, status regarding considering oneself under risk of cancer was found to affect general health negatively $(p<0.01)$, and age and education level was found to positively affect healthy lifestyle behavior $(p<0.05)$.
\end{abstract}

Conclusion: Status regarding having a cancer patient in the family was found to not affect general health status and affect healthy lifestyle behavior positively in nursing and midwifery students.

Keywords: Cancer, familial history, general health, healthy lifestyle behavior, student

\section{Introduction}

Cancer is an important health problem throughout the world and in Turkey, causing the most deaths second to only heart diseases. According to data from 2012, 14.1 million individuals in the world were diagnosed with cancer and 8.2 million individuals lost their lives because of cancer (1). The cancer incidence in Turkey is similar to the world and the developing countries of the world, and the male-female total incidence of cancer in Turkey is 228.6 in a hundred thousand. A 13.5 in a hundred thousand increase in cancer incidence from 2010 to 2011 can be seen in Turkey (2). The most common types of cancer worldwide are lung, liver, stomach, colorectal, breast, and esophageal cancers, respectively (3). In Turkey, breast, thyroid, and colorectal cancers in women, and lung, prostate, and colorectal cancers are seen most common (2).In the phase of treatment and care, cancer affects the quality of life of both the patient and his/her relatives negatively from many aspects such as physical, emotional, and economic $(4,5)$. Additionally, the perception of cancer as a disease that threatens life, fear of losing the patient, feelings of desperation, and difficulties in coping may disrupt the well beings, relationships, sleep patterns, and general health of patient's relatives (6-11).

Since cancer develops because of $5-10 \%$ genetic and $90-95 \%$ environmental reasons (12), it is considered a preventable disease (3). Although the genetic inclination rate is interpreted as low, the risk for cancer increases in individuals with genetic predilection combined with environmental factors. This can cause family members and relatives of cancer patients to worry about their health more (13). For his reason, the general health status of individuals who have cancer patients in their families should be determined in the early period. Protection from cancer is the most important method of preventing cancer publicly, and it is very important in protection from cancer to adopt healthy lifestyle behavior and apply those. Healthy lifestyle behavior is defined as behavior that serves individuals in maintaining and increasing their well being. These 
behaviors include sufficient and balanced nutrition, stress management, regular physical activity, efficient spiritual development, positive interpersonal relationships, and taking responsibility for one's protection and improvement of health (14). In a study by Spring et al (15), the effective application of healthy lifestyle behaviors in health systems and the society is stated to cause a reduction in cancer prevalence. In this context, nursing and midwifery students, who will assume effective roles in the protection of individuals' health, their treatment, and care, should exhibit healthy behavior and become role models in order to be able to inform healthy/sick individuals and the society on the development of positive health behavior for protection form cancer and provide counseling.

In recent years, it has become very important to raise the awareness levels of individuals under genetic risk for cancer and guide them to gain health improvement behaviors. In this context, determining how young people related to individuals with cancer, who have strong emotional ties to those individuals, are affected by cancer may be effective in strengthening their coping skills and adding healthy years to their lives. This study was performed with the aim of comparatively exhibiting the effect of status regarding having a cancer patient among family (mother, father, sibling) or relatives (uncle, aunt, grandfather, grandmother, niece) on the general health conditions and healthy lifestyle behavior of nursing and midwifery students.

\subsection{Sample}

\section{Methods}

The universe of this comparative and descriptive study consisted of 864 students studying at the nursing and midwifery departments of a university between November $15^{\text {th }}$ and December $15^{\text {th }} 2015.713$ students who continued their studies in the period the study was performed, weren't diagnosed with cancer, accepted to participate, and filled out the data collection forms completely were included in the sample. In this context, the participation rate for the study was $82.5 \%$.

\subsection{Data collection tools}

Data was collected using the student identification form, the General Health Questionnaire-12, and the Healthy Lifestyle Behavior Scale-II. Student Identification Form: In this form prepared by the researchers according to literature, the personal information of the students and their thoughts on cancer were questioned with 22 questions.The General Health Questionnaire-12 (GHQ-12): This self report scale is a scale that aims to demonstrate mental disorders among the public and participants in the clinical setting except for psychiatry questions mental symptoms pertaining to the last week. The scale was developed in 1972 by David Goldberg. The scale has $12,28,30$, and 60 item forms. The 12 item form of the questionnaire is widely preferred since it has high accuracy and specificity in separating cases and can be used in various socio cultural settings. Its Turkish translation and validity and reliability studies were performed by Kilic (16). Each item has four answers ( 1 , never happens; 2 , just as always; 3 , more than ever; 4 , very often). The scale is scored by assigning 0 points for the first two choices and 1 for the last two choices. The highest score that can be taken from the scale is 12 while the lowest is 0 . Those who take 4 points or more form the scale are considered to have taken "high" scores, those who take 2 or 3 points are considered to have taken medium scores, and those who take less than 2 are considered to have taken "low" scores. Those with 4 or higher points from the scale are considered "the group under risk of mental diseases" (16). The Cronbach alpha value of the scale in this study was found to be 0.82.The Healthy Lifestyle Behavior Scale-II (HLBS-II): The scale was developed in 1996 by Walker et al, and translated into Turkish and tested for validity and reliability in 2008 by Bahar et al. The scale consists of 52 items and six sub dimensions, namely spiritual development, interpersonal relationships, nutrition, physical activity, health responsibility, and stress management. The scale is evaluated in a 4 way likert type scoring with the options "never (1)", "sometimes (2)", "often (3)", and "regularly (4)". The lowest score that can be taken from the whole scale is 52 while the highest is 208 . Higher scores indicate healthy lifestyle behavior on more desired levels (17). The Cronbach alpha value of the scale in this study was found to be 0.91 .

\subsection{Ethical permission}

Written permission from the ethical board of a university was taken for the study to be performed (Decision no: 2015-10/14). Additionally, written permission was taken from the institution where the study was performed. Researchers informed the students on the aim and importance of the study. Then, informed consent was taken from the students who agreed to participate. The study was conducted in accordance with the ethical standards of the Helsinki declaration.

\subsection{Statistical Analysis}

Data were analyzed using the SPSS 16.0 program. Descriptive (mean, SD [standard deviation], range and frequency), comparative (Chi-square test for qualitative data, student $t$ test, Mann-Whitney $\mathrm{U}$ test and Kruskal-Wallis test for independent groups) and correlational (Pearson correlation) statistics were used to analyze the data. A level of significance of $\mathrm{p}<0.05$ was established prior to data collection.

DOI: 10.9790/1959-0601026370 www.iosrjournals.org $\quad 64$ |Page




\section{Results}

While $69.1 \%$ of the students studied at the nursing department, $30.9 \%$ studied at the midwifery department. The average age of the students was $19.90 \pm 1.44$ years, and $75.5 \%$ were female. $32.1 \%$ of the participants were in their junior year, $98.3 \%$ were single, and $72.1 \%$ resided in dormitories. $9.4 \%$ of the students were overweight, $4.6 \%$ were obese, $12.3 \%$ smoked, and $6.6 \%$ used alcohol. Additionally, $6.5 \%$ of the students had a chronic disease (migraine, diabetes, asthma, hyperthyroid, etc). $72.4 \%$ of the students evaluated their health as fine and $83.5 \%$ evaluated their family relationships as fine. $71.1 \%$ of the students stated their academic success to be on an average level. Among the students, $23.7 \%$ had a cancer patient in their immediate families or among their relatives, and this ratio was $13.6 \%$ regarding only immediate family members. The prevalence of lung cancer (22.4\%), breast cancer (14.3\%), and colon cancer (11\%) were higher among the families and relatives of the students. While $19.9 \%$ of the students thought they were under risk of cancer, only $17.5 \%$ stated that they had sufficient information on preventing cancer. The students termed the most important factors that cause cancer as stress (38.6\%), smoking (22.3\%), and genetic predilection (20.3\%). 78.4\% of the students stated that the risk factors for cancer could be controlled in order to fight cancer. To the question "What is the most important personal intervention you applied in order to fight cancer?" $50.1 \%$ of the students gave the answer not smoking and $14.9 \%$ gave the answer stress management (Table 1).

In Table 2, the general health levels and the healthy lifestyle behaviors of the students were shown. The general health levels $(2.57 \pm 2.80)$ and healthy lifestyle behaviors of the students who participated $(128.07 \pm 19.11)$ were found to be on an average level. In the HLBS-II, the students took the highest scores from the spiritual development sub dimension $(26.41 \pm 4.82)$, and the lowest score from the physical activity sub dimension (15.98 \pm 4.44$)$. It was determined that the general health statuses of the students with cancer patients in their families were affected on a higher level, although this difference was not statistically meaningful ( $p>0.05$ ). Additionally, the health responsibility and interpersonal relationships score averages, as well as the total scores of the students who had a cancer patient in their family were found to be higher compared to the students who didn't $(\mathrm{p}<0.05)$. Accordingly, the health responsibility, interpersonal relationships, and total healthy lifestyle behavior score averages of the students who had a cancer patient among family or relatives were found to be higher.The comparison of the students' status regarding having a cancer patient among family or relatives with certain variables was given in Table 3. Accordingly, while status regarding having a cancer patient among family and relatives does not affect their academic success, family relations, or smoking status ( $>0.05)$, it affects health evaluation, status regarding considering oneself under risk of cancer, and thoughts on having sufficient information to fight cancer on meaningful levels $(\mathrm{p}<0.05)$. It was thus determined that students with a cancer patient among family and relatives, when compared to those who don't, don't perceive their health as fine, think they carry more risk for cancer, and have more information on preventing cancer.

While the age, gender, department studied a, residence, family member or relative with cancer, presence of chronic diseases, and having sufficient information for preventing cancer didn't affect the general health levels of students who have a cancer patient among family and relatives ( $p>0.05)$, year of study and considering oneself under risk of cancer did $(\mathrm{p}<0.05)$. Accordingly, the general health levels of students who are in their freshman year and consider themselves under risk of cancer were worse. Additionally, the age, year of study, and status regarding having sufficient information on preventing cancer affected their healthy lifestyle behavior statistically $(\mathrm{p}<0.05)$. In this context, as the age and education level of the students increased, so did their healthy lifestyle behaviors.

\section{Discussion}

Genetic predilection to cancer increases the prevalence of many types of cancer such as colorectal, esophagus, and larynx cancers (18). However, it is not known if the general health levels of family members or relatives under risk of cancer are affected or if a difference in their healthy lifestyle behaviors towards protection from cancer occurs. Because of the limited nature of studies on the effect of status regarding having a cancer patient among family or relatives on general health levels and healthy lifestyle behaviors of nursing and midwifery students both in Turkey and throughout the world, the findings of the study were discussed generally by taking into consideration studies on individuals who have cancer patients among family or relatives. In our study, it was determined that almost a quarter of the students had a cancer patient among family or relatives, and that this rate is $13.6 \%$ among family members. In a study conducted with university students, it was found that $36.4 \%$ of the participants had a cancer patient in their close environment and that $10.4 \%$ were immediate family, and $71.6 \%$ were extended family (19). Similarly, in another study where nursing and midwifery students were also present, it was found that $30.1 \%$ of the students had a history of cancer within their immediate family, and $63.8 \%$ had a history of cancer among extended family. When the prevalence of cancer is taken into consideration, it becomes very important to raise awareness on protection from cancer, especially in the younger generation. 
In our study, nearly four fifths of the students didn't consider themselves under risk of cancer. In another study, $26.8 \%$ of the participants with a history of cancer in their family were found to think they had a higher possibility than most people of cancer (20). In a study by Ilgaz and Gozum (21), those with a history of cancer in their family were found to be afraid of cancer themselves. In a study performed by Smith et al, (22) with women, only $24 \%$ of individuals with cancer among their immediate families were found to be worried about cancer. The findings of our study show that most of the students were not aware of the importance of genetic predilection when considering cancer risk. In preventing cancer, it is very important to raise awareness in every section of society, especially health sciences students. Only a fifth of the students in our study stated that they had sufficient knowledge regarding preventing cancer. In another study, most of the students stated cancer to be a preventable disease and thought that their knowledge on caner was on a good level (23). The findings of our study can be explained by nearly a third of the students being in their freshman year and thus not having learned theoretically the relationship between cancer and genetic predilection.

Bad dietary habits, obesity, smoking, alcohol consumption, physical inactivity, high risk sexual behavior, and exposure to the sun without protection are all among preventable causes for cancer (15). In our study, the students stated the most important factors causing cancer as stress, smoking, and genetic predilection. In a study by Coban et al (23), 98\% of the students stated smoking to be a cause of cancer while $90.2 \%$ stated alcohol consumption as one. In another study, the ratio of students that stated that lifestyle and certain habits have an effect on cancer was found to be $86.8 \%$ (19). The fact that the students in our study stated stress to be first among cancer risk factors shows that they need psycho social support. Difficulties a student encounters during education, the traumatic events he/she experiences, and difficulties in human relations may cause disruptions in general health condition and mental status when the necessary precautions are not taken (24). In our study, even though there was no meaningful difference between the general health conditions of students with and without a cancer patient among family or relatives, being affected by the situation was found to be higher. In another study, an increase in the affectivity of $60.9 \%$ of the relatives of patients was found with a fifth having bad general health levels (4). The findings of our study may have arisen from the students being away from the individual with cancer, missing the individual, anxiety regarding carrying risk of disease, and difficulties encountered during education. In this context, examining general health condition, which affects the personal and occupational development of the students, during education can help identifying the problems of the students early and improve coping skills.

The most important factor in society based protection from cancer is lifestyle related habits. In this context, individuals realizing healthy lifestyle behaviors such as avoiding smoking, healthy nutrition, and regular physical activity will be the most important intervention possible. One of the factors that have an effect on the acquisition of healthy lifestyle behaviors is the perception of the disease as a threat (25). In our study, the healthy lifestyle behaviors of students with a cancer patient among family or relatives were on a better level compared to those without. In other studies, status regarding having a cancer patient among family or relatives was found to affect early diagnosis behavior positively, increase knowledge on cancer, and provide improvement in healthy lifestyle behavior (26-28). Contrary our study, some studies in literature have found that status regarding having a cancer patient among family or relatives doesn't affect behavior regarding protection from cancer (20,29-32). It is pleasing that according to the findings of our study, students under genetic risk show positive behavior for protection from cancer.

In our study, the dietary habits of the students with regard to protection from cancer were found to be on an average level, and their physical activity habits were found to be poor. In other studies where the behaviors of students with regard to protection from cancer were examined, similar results were reached $(19,33,34)$. The findings of our study may have risen form reasons such as most of the students residing in dormitories, the students spending most of their day at school, and the insufficiency of sports fields. In our study, the general health levels of students who were in their freshman year and had a cancer patient among family or relatives, and students who consider themselves under risk of cancer were found to be lower. In another study, the risk of cancer was found to affect health perception negatively (20).In our study, the healthy lifestyle behaviors of the students were found to increase with increasing age and education levels. Other studies conducted with students also have found that age and education level affect healthy lifestyle behaviors positively (14,35-39). The findings of our study show that students should be made aware of preventing cancer starting in their freshman year and hat high risk groups should be determined and supported.

\section{Conclusion}

According to our findings, it was determined that nearly a quarter of the students had a cancer patient among family or relatives and that these students considered themselves under greater risk of cancer. Status regarding having a cancer patient in the family was found to not affect general health status and affect healthy lifestyle behavior positively in nursing and midwifery students. Additionally in our study, considering oneself under risk of cancer was found to affect general health levels negatively, and age and education level were 
found to affect healthy lifestyle behavior positively. According to these findings, it can be suggested that course contents regarding protection from cancer should be given in each year of education, evaluations that will exhibit the healthy lifestyle behaviors of the students should be periodically performed during their professional education, topics shown to be insufficiently understood should be determined and activities such as symposiums and conferences should be performed, and students with a cancer patient among their family or relatives with genetic risk should be provided psychosocial support and counseling.

\section{References}

[1] Torre LA, Bray F, Siegel RL, Ferlay J, Lortet-Tieulent J, Jemal A. Global cancer statistics, 2012. CA Cancer J Clin. 2015; 65, 87108.

[2] Turkey Cancer Statistics 2015. The Ministry of Health Public Health Agency Eds Sencan I and Keskinkilic B. Turkey.

[3] American Cancer Society, Cancer Facts \& Figures 2014. Available from: http://www. cancer.org/acs/ groups/content/ @ research/documents/webcontent/acspc-042151.pdf (accessed December 20, 2015).

[4] Civi S, Kutlu R, Celik HH. Depression status and the factors affecting the quality of life in the relatives of the patients with cancer. Gulhane Medical Journal. 2011; 53: 248-253.

[5] Yakar HK, Pınar R. Evaluation of quality of life among family caregivers of patients with cancer. Journal of Nursing Research Development. 2013; 15: 1-16.

[6] Pitceathly C, Maguire P. The psychological impact of cancer on patients' partners and other key relatives: a review. Eur J Cancer. 2003; 39: 1517-1524.

[7] Hagedoorn M, Kreicbergs U, Appel C. Coping with cancer: The perspective of patients' relatives. Acta Oncol. 2011 ; 50: $205-211$.

[8] Friqriksdottir N, Saevarsdottir T, Halfdanardottir SI, Jónsdóttir A, Magnúsdóttir H, Olafsdóttir KL, Guðmundsdóttir G, Gunnarsdóttir S. Family members of cancer patients: Needs, quality of life and symptoms of anxiety and depression. Acta Oncol. 2011; 50: 2152-2158.

[9] Northouse LL, Katapodi MC, Schafenacker AM, Weiss D. The impact of caregiving on the psychological well-being of family caregivers and cancer patients. Semin Oncol Nurs. 2012; 28: 236-245.

[10] Bevans MF, Sternberg EM. Caregiver burden, stress, and health effects among family caregivers of adult cancer patients. JAMA. 2012; 307: 398-403.

[11] Bag B. Depression in cancer patients. Current Approaches in Psychiatry. 2014; 6: 186-198.

[12] Ozkan C, Celik I. Nutrition and cancer. Journal of Academic Geriatrics. 2009; 1: 132-138.

[13] Mohandas KM. Genetic predisposition to cancer. Current Science. 2001; 81: 482-489.

[14] Aksoy T, Uçar H. Healthy lifestyle behaviors of nursing students. Journal of Hacettepe University Faculty of Nursing. 2014; 1: 5367.

[15] Spring B, King AC, Pagoto SL, Horn LV, Fisher JD. Fostering Multiple Healthy Lifestyle Behaviors for Primary Prevention of Cancer. American Psychological Association. 2015; 70: 75-90.

[16] Kilic C. General health Questionnaire: Reliability and validity studies. Turkish Journal of Psychiatry. 1996; 7: 3-10.

[17] Bahar Z, Beser A, Gordes N, Ersin F, Kisal A. Healthy life style Bbhavior scale II: A reliability and validity study. Cumhuriyet UniversityJournal of Nursing School. 2008; 12: 1-13.

[18] Turati F, Negri E, La Vecchia C. Family history and the risk of cancer: Genetic factors influencing multiple cancer sites. Expert Rev Anticancer Ther. 2013; 14: 1-4.

[19] Bayrak U, Gram E, Mengeş E, Okumuş ZG, Sayar HC, Skrijelj E, Açıkgöz A, Çehreli R, Ellidokuz H. The knowledge and attitude of university students about health habitude and cancer. DEU Journal of Medicine. 2010; 24: 95-104.

[20] Caman OK, Bilir N, Ozcebe H. Are family history of cancer and perceived cancer risk associated with cancer preventive behaviors? Firat Med J. 2014; 19: 95-100.

[21] Ilgaz A, Gözüm S. Priority targets of cancer screening is first-degree relatives. Dokuz Eylul University School of Nursing Electronic Journal. 2014; 7: 345-353.

[22] Smith WD, Greene PA, Kratt PP, Pulley P, Weiss HL, Siegfried N, Gore SA. The impact of a family history of breast cancer on screening practices and attitudes in low-1ncome, Rural, African American Women. J Womens Health. 2003; 12: 779-787.

[23] Coban A, Kavlak O, Ozbasaran F. The evaluation of school of health students' knowledge and behavior of healthy life-styles of related to importance to prevent cancer. Asian Pacific J Cancer Prev. 2010; 11: 773-776.

[24] Ozturk C, Aktas B. The investigation of the nursing students' state of health and some of the features affecting it. Ataturk University School of Nursing Journal. 2007; 10: 58-65.

[25] Tashiro J. Exploring health promoting lifestyle behaviors of Japanese college women: Perceptions, practices, and issues. Health Care Women Int. 2002; 23: 59-70.

[26] Kilic D, Saglam R, Kara O. The examination of the factors affecting the awereness of breast cancer in college students. The Journal of Breast Health. 2009; 5: 195-199.

[27] Bostean G, Crespi CM, McCarthy WJ. Associations among family history of cancer, cancer screening and lifestyle behaviors: A population-based study. Cancer Causes Control. 2013; 24: 1491-1503.

[28] Gunaydin C, Gencturk N. Early diagnosis behavior in Turkish women with and without a family history of cervical cancer. Asian Pac J Cancer Prev. 2015; 16: 401-406.

[29] Kasparian NA, McLoone JK, Meiser B, Butow PN, Simpson JM, Mann GJ. Skin cancer screening behaviours among individuals with a strong family history of malignant melanoma. Brit J Cancer. 2010; 103: 1502-1509.

[30] Santos EM, Lourenço MT, Rossi BM. Risk perception among Brazilian individuals with high risk for colorectal cancer and colonoscopy. Hered Cancer Clin Pract. 2011; 28: 4.

[31] Townsend JS, Steele CB, Richardson LC, Stewart SL. Health behaviors and cancer screening among Californians with a family history of cancer. Genet Med. 2013; 15: 212-221.

[32] Bektas M, Malak AT, Yumer AS, Korkmaz M, Özkan A. Turkish university students' nutritional habits regarding cancer prevention and healthy lifestyles. Asian Pacific J Cancer Prev. 2010; 11: 1347-1350.

[33] Nogay NH, Akinci AC, Sert H, Kurtulus Z, Gedik S. Dietary habits contributing to the cancer prevention among health college students in Turkey. Asian Pacific J Cancer Prev. 2012; 13: 963-968.

[34] Ay S, Yenikkerem E, Calım SI, Yazıcı M. Health-promoting lifestyle behaviour for cancer prevention: A survey of Turkish university students. Asian Pacific J Cancer Prev. 2012; 13: 2269-2277. 
[35] Hsiao YC, Chen MY, Gau YM, Hung LL, Chang SH, Tsai HM. Short-term effects of a health promotion course for Taiwanese nursing students. Public Health Nursing. 2005; 22: 74-81.

[36] Ertop NG, Y1lmaz A, Erdem Y. Healthy lifestyle of university students. Kirikkale University Journal of Medicine. 2012; $14: 1$-7.

[37] Alpar Ş, Şenturan L, Karabacak Ü, Sabuncu N. Change in the health promoting lifestyle behaviour of Turkish university nursing students from beginning to end of nurse training. Nurse Education in Practice. 2008; 8: 382-388.

[38] Al-Kandari F, Vidal VL, Thomas D. Health promoting lifestyle and body mass index among college of nursing students in Kuwait: A correlational study. Nurs Health Sci. 2008; 10: 43-50.

[39] Yeh L, Chen CH, Wang CJ, Wen MJ, Fetzer S. A preliminar ystudy of a healthy-lifestyle-promoting program for nursing students in Taiwan. Journal of Nursing Education. 2006; 44: 563-566.

Table 1. The Sociodemographic Characteristics of the Students $(n=713)$

\begin{tabular}{|c|c|c|}
\hline Variables & Mean \pm SD & Range \\
\hline \multirow[t]{2}{*}{ Age (year) } & $19.90 \pm 1.44$ & $17-31$ \\
\hline & $\mathbf{n}$ & $\%$ \\
\hline \multicolumn{3}{|l|}{ Department } \\
\hline Nursing & 493 & 69.1 \\
\hline Midwifery & 220 & 30.9 \\
\hline \multicolumn{3}{|l|}{ Classroom } \\
\hline $\mathrm{I}$ & 193 & 27.1 \\
\hline II & 219 & 30.7 \\
\hline III & 229 & 32.1 \\
\hline IV & 72 & 10.1 \\
\hline \multicolumn{3}{|l|}{ Gender } \\
\hline Famale & 538 & 75.5 \\
\hline Male & 175 & 24.5 \\
\hline \multicolumn{3}{|l|}{ Marital status } \\
\hline Married & 12 & 1.7 \\
\hline Single & 701 & 98.3 \\
\hline \multicolumn{3}{|l|}{ Living place } \\
\hline At home with parents & 78 & 10.9 \\
\hline At home with colleagues & 121 & 17.0 \\
\hline Dormitory & 514 & 72.1 \\
\hline \multicolumn{3}{|l|}{ Body Mass Index } \\
\hline$<18.5$ & 73 & 10.2 \\
\hline $18.5-24.9$ & 541 & 75.8 \\
\hline $25.0-29.9$ & 67 & 9.4 \\
\hline$>30$ & 32 & 4.6 \\
\hline \multicolumn{3}{|l|}{ Smoking status } \\
\hline Yes & 88 & 12.3 \\
\hline Never used & 596 & 83.6 \\
\hline Forwent & 29 & 4.1 \\
\hline \multicolumn{3}{|l|}{ Alcohol consumption status } \\
\hline Yes & 47 & 6.6 \\
\hline Never used & 648 & 90.9 \\
\hline Forwent & 18 & 2.5 \\
\hline \multicolumn{3}{|l|}{ Chronic disease } \\
\hline Yes & 46 & 6.5 \\
\hline No & 667 & 93.5 \\
\hline \multicolumn{3}{|l|}{ General helath perception } \\
\hline Good & 516 & 72.4 \\
\hline Moderate & 175 & 24.5 \\
\hline $\mathrm{Bad}$ & 22 & 3.1 \\
\hline \multicolumn{3}{|l|}{ Family relations } \\
\hline Good & 596 & 83.5 \\
\hline Moderate & 93 & 13.0 \\
\hline $\mathrm{Bad}$ & 24 & 3.5 \\
\hline \multicolumn{3}{|l|}{ Academic success level } \\
\hline Good & 175 & 24.5 \\
\hline Moderate & 507 & 71.1 \\
\hline $\mathrm{Bad}$ & 31 & 4.3 \\
\hline
\end{tabular}


Table 2. Presence of Cancer in the Family or Relatives of the Students and Their Thoughts Regarding Cancer

\begin{tabular}{|c|c|c|}
\hline Variables & $\mathbf{n}$ & $\%$ \\
\hline \multicolumn{3}{|l|}{ Presence of cancer among family or relatives } \\
\hline Yes & 169 & 23.7 \\
\hline No & 544 & 76.3 \\
\hline \multicolumn{3}{|l|}{ Family member or relative with cancer* } \\
\hline Family member & 23 & 13.6 \\
\hline Relative & 146 & 86.4 \\
\hline \multicolumn{3}{|l|}{ Type of cancer in family or among relatives* } \\
\hline Lung Cancer & 38 & 22.4 \\
\hline Breast Cancer & 24 & 14.3 \\
\hline Colon cancer & 17 & 11.0 \\
\hline Prostate cancer & 14 & 8.3 \\
\hline Uterus cancer & 13 & 7.6 \\
\hline Stomach cancer & 11 & 6.4 \\
\hline Pancreas cancer & 10 & 5.8 \\
\hline Other** & 41 & 24.2 \\
\hline \multicolumn{3}{|l|}{ Considering oneself under risk of cancer } \\
\hline Yes & 142 & 19.9 \\
\hline No & 571 & 80.1 \\
\hline \multicolumn{3}{|l|}{ Having sufficient information for preventing cancer } \\
\hline Yes & 125 & 17.5 \\
\hline Partially & 438 & 61.4 \\
\hline No & 150 & 21.1 \\
\hline \multicolumn{3}{|l|}{ Most important factor causing cancer } \\
\hline Stress & 275 & 38.6 \\
\hline Smoking & 159 & 22.3 \\
\hline Genetic predilection & 145 & 20.3 \\
\hline Environmental elements (radiation, sunlight ect.) & 74 & 10.4 \\
\hline Alcohol & 22 & 3.1 \\
\hline Wrong diet & 21 & 2.9 \\
\hline Obesity & 9 & 1.3 \\
\hline Insufficient physical activity & 5 & 0.7 \\
\hline Presence of other diseases & 3 & 0.4 \\
\hline \multicolumn{3}{|c|}{ Whether risk factors for cancer can be controlled for preventing cancer } \\
\hline Yes & 559 & 78.4 \\
\hline No & 43 & 6.0 \\
\hline Don’t know & 111 & 15.6 \\
\hline \multicolumn{3}{|c|}{ Most important personal intervention for preventing cancer } \\
\hline Not smoking & 357 & 50.1 \\
\hline Stress management & 106 & 14.9 \\
\hline Healthy diet & 93 & 13.0 \\
\hline Health controls for risk factors & 60 & 8.4 \\
\hline Avoiding radiation and sunlight & 36 & 5.0 \\
\hline Weight control & 32 & 4.5 \\
\hline Regular exercise & 22 & 3.1 \\
\hline Avoiding chemical products & 7 & 1.0 \\
\hline
\end{tabular}

$* \mathrm{n}=169 * *$ Other types of cancer: Liver, bladder, thyroid, skin, esophagus, cervix and soft tissue cancers.

***The number $\mathrm{n}$ increased because of more than one option being marked. 
Table 3. The Distribution of the General Health Questionnaire and Healthy Lifestyle Behavior Scala Score Averages of the Students According to Their Status Regarding the Presence of Cancer in Their Families of Among Their Relatives

\begin{tabular}{|c|c|c|c|c|c|}
\hline \multirow[t]{2}{*}{ Scalas } & \multirow[t]{2}{*}{ General } & \multicolumn{2}{|c|}{$\begin{array}{l}\text { Status regarding having a cancer } \\
\text { patient among family or relatives of } \\
\text { the students }\end{array}$} & \multirow[b]{2}{*}{$\mathbf{t}$} & \multirow[b]{2}{*}{$\mathbf{p}$} \\
\hline & & $\begin{array}{c}\text { Yes } \\
n=169\end{array}$ & $\begin{array}{c}\text { No } \\
n=544\end{array}$ & & \\
\hline \multicolumn{6}{|l|}{ General Health Questionnaire-12 } \\
\hline & $2.57 \pm 2.80$ & $2.90 \pm 3.09$ & $2.47 \pm 2.70$ & 1.734 & 0.083 \\
\hline \multicolumn{6}{|c|}{ Healthy Lifestyle Behavior Scala-II } \\
\hline Health responsibility & $21.54 \pm 4.49$ & $22.39 \pm 4.42$ & $21.28 \pm 4.48$ & 2.802 & $0.005^{* *}$ \\
\hline Physical activity & $15.98 \pm 4.44$ & $16.39 \pm 4.55$ & $15.86 \pm 4.41$ & 1.355 & 0.176 \\
\hline Nutrition & $20.11 \pm 3.89$ & $20.30 \pm 4.09$ & $20.05 \pm 3.84$ & 0.723 & 0.470 \\
\hline Spiritual development & $26.41 \pm 4.82$ & $26.71 \pm 4.67$ & $36.32 \pm 4.87$ & 0.909 & 0.364 \\
\hline Interpersonal relationships & $25.34 \pm 4.48$ & $26.28 \pm 4.30$ & $25.05 \pm 4.50$ & 3.147 & $0.002 * *$ \\
\hline Stress management & $18.66 \pm 3.54$ & $18.95 \pm 3.68$ & $18.57 \pm 3.49$ & 1.229 & 0.219 \\
\hline Total & $128.07 \pm 19.1$ & $131.04 \pm 19.78$ & $127.15 \pm 18.83$ & 2.317 & $0.021 *$ \\
\hline
\end{tabular}

Table 4. The Comparison of the Students' Status Regarding Having a Cancer Patient Among Family or Relatives With Certain Variables

\begin{tabular}{|c|c|c|c|c|c|c|}
\hline \multirow{3}{*}{ Variables } & \multicolumn{4}{|c|}{$\begin{array}{c}\text { Status regarding having a cancer patient among family or } \\
\text { relatives of the students }\end{array}$} & \multirow{3}{*}{$\mathbf{X}^{2}$} & \multirow{3}{*}{$\mathbf{p}$} \\
\hline & \multicolumn{2}{|c|}{ Yes } & \multicolumn{2}{|c|}{ No } & & \\
\hline & $n=169$ & $\%$ & $\mathrm{n}=544$ & $\%$ & & \\
\hline \multicolumn{5}{|c|}{ Academic success level } & \multirow{4}{*}{2.516} & \multirow{4}{*}{0.284} \\
\hline Good & 48 & 28.4 & 127 & 23.0 & & \\
\hline Moderate & 116 & 68.6 & 391 & 71.9 & & \\
\hline $\mathrm{Bad}$ & 5 & 3.0 & 26 & 4.8 & & \\
\hline \multicolumn{5}{|l|}{ Family relations } & \multirow{4}{*}{2.498} & \multirow{4}{*}{0.287} \\
\hline Good & 148 & 87.5 & 461 & 84.7 & & \\
\hline Moderate & 16 & 9.5 & 77 & 14.2 & & \\
\hline Bad & 5 & 3.0 & 6 & 1.1 & & \\
\hline \multicolumn{5}{|c|}{ General helath perception } & \multirow{4}{*}{8.852} & \multirow{4}{*}{$0.012 *$} \\
\hline Good & 120 & 71.0 & 396 & 72.8 & & \\
\hline Moderate & 38 & 22.4 & 137 & 25.0 & & \\
\hline Bad & 11 & 6.6 & 11 & 2.1 & & \\
\hline \multicolumn{5}{|l|}{ Simoking status } & \multirow{4}{*}{0.911} & \multirow{4}{*}{0.634} \\
\hline Yes & 21 & 12.5 & 67 & 12.3 & & \\
\hline Never used & 139 & 82.2 & 457 & 84.0 & & \\
\hline Forwent & 9 & 5.3 & 20 & 3.7 & & \\
\hline \multicolumn{5}{|c|}{ Considering oneself under risk of cancer } & \multirow{3}{*}{83.109} & \multirow{3}{*}{$0.000 * *$} \\
\hline Yes & 75 & 44.4 & 67 & 12.3 & & \\
\hline No & 94 & 55.6 & 477 & 87.7 & & \\
\hline \multicolumn{5}{|c|}{ Having sufficient information for preventing cancer } & \multirow{4}{*}{15.736} & \multirow{4}{*}{$0.000 * *$} \\
\hline Yes & 43 & 25.4 & 82 & 15.1 & & \\
\hline Partially & 105 & 62.2 & 333 & 61.2 & & \\
\hline No & 21 & 12.4 & 129 & 23.7 & & \\
\hline
\end{tabular}

$* \mathrm{p}<0.05 ; \quad * * \mathrm{p}<0.01$ 